\title{
The Fuzziness in Molecular, Supramolecular, and Systems Chemistry
}

\author{
Pier Luigi Gentili ${ }^{D}$ \\ Department of Chemistry, Biology, and Biotechnology, Università degli Studi di Perugia, Via elce di sotto 8, \\ 06123 Perugia, Italy; pierluigi.gentili@unipg.it; Tel.: +39-075-585-5573
}

Received: 6 August 2020; Accepted: 7 August 2020; Published: 10 August 2020

check for updates

\section{Introduction}

The global challenges of the XXI century require a more in-depth analysis and investigation of complex systems [1]. A promising research line to better understand complex systems, and propose new algorithms and computing devices is natural computing. Natural computing is based on a fundamental rationale: every causal phenomenon can be conceived as a computation and every distinguishable physicochemical state of matter and energy can be used to encode information. Any physicochemical law can be exploited to make computations. For instance, quantum mechanics laws can be exploited to make quantum computing; the chemical kinetic laws can be used to make chemical computing; the laws of chaos to make chaos-computing, etc. On the other hand, we might draw inspiration from living beings with the exclusive attribute of using matter and energy to encode, collect, store, process, and send information [1,2]. Living beings show different information systems. Their basic information system is the cell, also called the biomolecular information system (BIS). In most multicellular organisms, we encounter nervous systems that constitute neural information systems (NISs). The defense systems that help repel antigens and disease-causing organisms are defined as immune information systems (IISs). Finally, most living beings live in societies, and the resulting aggregations constitute the so-called social information systems (SISs).

\section{Artificial Intelligence and Fuzzy Logic}

Among the natural information systems, particularly alluring for facing XXI century challenges, is the human nervous system (HNS). Its performances are astonishing. Based on a complex architecture of billions of nerve cells, our nervous system allows us to handle accurate and vague information by computing with numbers and words. Furthermore, it allows us to recognize variable patterns quite easily and make decisions in complex situations. Therefore, it is worthwhile trying to understand how it works and mimic it by developing artificial intelligence (AI). Within AI, fuzzy logic stands out as a good model of the human ability to compute with words and make decisions in complex circumstances [3,4]. Its descriptive and modeling power hinges on the structural and functional analogies it has with the HNS [5,6]. The entire architecture of the HNS is related to that of any fuzzy logic system. Our natural sensors play as fuzzifiers, our brain as a fuzzy inference engine, and our effectors as defuzzifiers. Every sensory system, physical and chemical, such as the visual or olfactory system, is constituted by a tissue of a spatially distributed array of sensory cells that behave as fuzzy sets $[5,6]$. Within each sensory cell, there is a multitude of sensory proteins that work as molecular fuzzy sets. The multiple information of any stimulus, i.e., its modality, intensity, spatial distribution, and time-evolution, is encoded hierarchically as degrees of membership to the molecular and cellular fuzzy sets. The imitation of these features allows us to design new artificial sensory systems with enhanced discriminative power due to different molecular fuzzy sets' parallel activity. A concrete example is the recent implementation of biologically inspired photochromic fuzzy logic systems that extend human vision to the UV $[7,8]$. 


\section{Neuromorphic Engineering and Chemical Artificial Intelligence}

The mimicry of nonlinear neural dynamics is a promising alternative strategy to approach human intelligence performances. Surrogates of neurons can be achieved through either oscillatory or excitable or chaotic chemical systems in solution (i.e., wetware) [9,10] or the solid phase (i.e., hardware) [11-13]. In this Special Issue, Szaciłowski and his team present an experimental characterization of an optoelectronic device, constituted by a polycrystalline cadmium sulfide electrode [14]. Such a device realizes a type of short-term plasticity, i.e., the paired-pulsed facilitation (PPF). The PPF consists of an enhancement in the postsynaptic current when the excitatory signal frequency increases. This short-term memory effect confers to the device an appreciable power of recognizing hand-written numbers. Szaciłowski's work blazes a trail for the optoelectronic implementation of neural network architectures that will allow the processing of fuzzy logic and recognition of variable patterns. Suffice to think that fuzzy logic has already been implemented through a pacemaker neuron model, such as the Belousov-Zhabotinsky reaction [15], and a chaotic neuron model, such as the "photochemical oscillator" [16,17]. When UV-visible radiation is chosen as a signal, it is straightforward to implement neuromodulation [18] and hence, fuzzy logic.

In the orthodox AI, fuzzy logic is processed through software running in digital electronic computers; it is even better if the electronic circuits are analog, since fuzzy logic is an infinite-valued logic. In the burgeoning field of chemical artificial intelligence (CAI) [19], unconventional chemical systems have been put forward for implementing fuzzy logic systems. Some examples can be found in the references [20-26]. The fundamental requirement is to have smooth analog input-output relationships between physicochemical variables, either linear or hyperbolic, but certainly not sigmoid. Sigmoid functions are adequate for processing discrete logics [27,28].

\section{Cellular Fuzziness}

The relentless investigation of the working principles of the cells or BISs has been revealing cellular fuzziness. Some proteins play within any cell as if they were the neurons of the "cellular nervous system" [6]. They are the protagonists of the signaling and genetic networks, and they make the cell capable of responding to ever-changing environmental conditions. As Fuxreiter points out in her perspective included in this Special Issue [29], often, a protein exists as a heterogeneous ensemble of conformers. For these proteins, the deterministic inference "amino-acidic sequence $\rightarrow 3 \mathrm{D}$ structure $\rightarrow$ function" is not applicable. In fact, the conformational ensemble may perform multiple functions, depending on the context. Such a collection of conformers looks like a macromolecular fuzzy set. The dynamical power of a protein to autonomously select a context-dependent function constitutes what we might name as its fuzzy inference engine. In their review, Jeffery and Liu tell us that there are moonlighting proteins in the metabolic network of a cell, in which one polypeptide chain performs more than one physiologically relevant biochemical or biophysical function [30]. The kind of function that is executed might depend on cellular localization, concentrations of substrates or ligands, or environmental stress. Any type of moonlighting protein is fuzzy because some of its copies can perform one function, some another, and some both functions simultaneously. As cellular conditions change due to metabolism and environmental conditions, the functions of these proteins change as well. Uversky informs us that within a cell, the supramolecular interactions between specific intrinsically disordered proteins and hybrid proteins, having ordered domains and intrinsically disordered protein regions, drive biological liquid-liquid phase transitions that form proteinaceous membrane-less organelles (PMLOs) [31]. PMLOs are intracellular hot spots that serve as organizers of cellular biochemistry. Such PMLOs are fuzzy, and their fuzziness resides in their compositional and compartmental variety and variability. Dodero and her team made the tangible experience of supramolecular fuzziness by investigating the interaction between a Transcription Factor and double-stranded DNA [32]. After annealing a proper DNA sequence and synthesizing a photosensitive surrogate of the GCN4 Transcription Factor, Dodero and her colleagues furnish experimental evidence of the protein-DNA complexation fuzziness by using different techniques, such as NMR, electrophoretic 
mobility shift assay, and circular dichroism spectroscopy. To monitor the conformational fuzziness of macromolecules and smaller molecules, Gentili relies upon the maximum entropy method to extract the distributions of conformers from any kinetic trace [6,33]. After determining the distribution, quantifying its fuzzy entropy is also possible [6,34].

\section{Non-Arrhenius Kinetics}

If we consider the conformational distributions of compounds, the original transition-state theory and the Arrhenius law might appear far-fetched. There is a peculiar distribution of conformers at every temperature, and every conformer traces its unique reactive path. It is not fair to define just one kinetic constant and one activation energy for all the coexistent conformers. It is necessary to add that both the original transition-state theory and the Arrhenius law have been already questioned by the most recent theoretical and experimental developments, as evidenced by Carvalho-Silva, Coutinho, and Aquilanti [35]. Quantum mechanical effects, such as tunneling and resonance, stochastic motions of particles in condensed environments, and non-equilibrium effects in classical and quantum formulations, are responsible for deviations from the traditional Arrhenius equation. In such situations, the transitivity function, defined in terms of the reciprocal of the apparent activation energy, measures the propensity for a reaction to proceed. The transitivity function provides a tool for implementing phenomenological kinetic models. In reference [36], Machado, Sanches-Neto, Coutinho, Mundim, Palazzetti, and Carvalho-Silva document the general scope of a transitivity code that can estimate the kinetic and thermodynamic parameters of physicochemical processes and deal with non-Arrhenius behavior.

\section{Conclusions and Perspectives}

This Special Issue's multidisciplinary contributions highlight that the theory of fuzzy set and fuzzy logic are valuable conceptual tools to understand the molecular and supramolecular world. Of course, quantum-mechanics already exists for this purpose, but fuzzy logic is becoming an alternative approach that might have still undiscovered common points with quantum logic $[37,38]$. Fuzzy logic appears particularly suitable for dealing with conformers. Although this approach is in its infancy, it is worthwhile pursuing it. It will allow us to describe any cell's activities, the constitutive elements of the human nervous system, and the immune system's performances more deeply. Such knowledge will be translated into new strategies to control the cellular processes and develop chemical artificial intelligence and chemical robots [6]. If cutting-edge technologies emerge from this approach, then, biomolecular, supramolecular, and systems chemistry will surely be considered fuzzy worldwide!

Funding: This research was funded by ANVUR grant number n.20/2017.

Acknowledgments: P.L. Gentili acknowledges all the contributors to this Special Issue, the anonymous reviewers of the papers published within this Special Issue, and Lola Huo for her valuable editorial assistance.

Conflicts of Interest: The author declares no conflict of interest.

\section{References}

1. Gentili, P.L. Untangling Complex Systems: A Grand Challenge for Science, 1st ed.; CRC Press, Taylor \& Francis Group: Boca Raton, FL, USA, 2018.

2. Cronin, L.; Walker, S.I. Beyond prebiotic chemistry. Science 2016, 352, 1174-1175. [CrossRef] [PubMed]

3. Zadeh, L.A. Fuzzy logic-a personal perspective. Fuzzy Sets Syst. 2015, 281, 4-20. [CrossRef]

4. Zadeh, L.A. Outline of a new approach to the analysis of complex systems and decision processes. IEEE Trans. Syst. Man Cybern. 1973, 3, 28-44. [CrossRef]

5. Gentili, P.L. The human sensory system as a collection of specialized fuzzifiers: A conceptual framework to inspire new artificial intelligent systems computing with words. J. Intell. Fuzzy Syst. 2014, 27, 2137-2151. [CrossRef]

6. Gentili, P.L. The Fuzziness of the Molecular World and Its Perspectives. Molecules 2018, 23, 2074. [CrossRef] 
7. Gentili, P.L.; Rightler, A.L.; Heron, B.M.; Gabbutt, C.D. Extending human perception of electromagnetic radiation to the UV region through biologically inspired photochromic fuzzy logic (BIPFUL) systems. Chem. Comm. 2016, 52, 1474-1477. [CrossRef]

8. Gentili, P.L.; Rightler, A.L.; Heron, B.M.; Gabbutt, C.D. Discriminating between the UV-A, UV-B and UV-C regions by novel Biologically Inspired Photochromic Fuzzy Logic (BIPFUL) systems: A detailed comparative study. Dyes Pigment. 2016, 135, 169-176. [CrossRef]

9. Gentili, P.L.; Giubila, M.S.; Germani, R.; Romani, A.; Nicoziani, A.; Spalletti, A.; Heron, B.M. Optical Communication among Oscillatory Reactions and Photo-Excitable Systems: UV and Visible Radiation Can Synchronize Artificial Neuron Models. Angew. Chem. Int. Ed. 2017, 56, 7535-7540. [CrossRef]

10. Gentili, P.L.; Giubila, M.S.; Germani, R.; Heron, B.M. Photochromic and luminescent compounds as artificial neuron models. Dyes Pigment. 2018, 156, 149-159. [CrossRef]

11. Marković, D.; Mizrahi, A.; Querlioz, D.; Grollier, J. Physics for neuromorphic computing. Nat. Rev. Phys. 2020. [CrossRef]

12. Lee, Y.; Lee, T.-W. Organic synapses for neuromorphic electronics: From brain-inspired computing to sensorimotor nervetronics. Acc. Chem. Res. 2019, 52, 964-974. [CrossRef] [PubMed]

13. Przyczyna, D.; Zawal, P.; Mazur, T.; Strzelecki, M.; Gentili, P.L.; Szaciłowski, K. In-materio neuromimetic devices: Dynamics, information processing and pattern recognition. Jpn. J. Appl. Phys. 2020, 59, 050504. [CrossRef]

14. Przyczyna, D.; Lis, M.; Pilarczyk, K.; Szaciłowski, K. Hardware Realization of the Pattern Recognition with an Artificial Neuromorphic Device Exhibiting a Short-Term Memory. Molecules 2019, 24, 2738. [CrossRef] [PubMed]

15. Gentili, P.L.; Horvath, V.; Vanag, V.K.; Epstein, I.R. Belousov-Zhabotinsky "chemical neuron" as a binary and fuzzy logic processor. Int. J. Unconv. Comput. 2012, 8, 177-192.

16. Gentili, P.L.; Dolnik, M.; Epstein, I.R. "Photochemical oscillator": Colored hydrodynamic oscillations and waves in a photochromic system. J. Phys. Chem. C 2014, 118, 598-608. [CrossRef]

17. Gentili, P.L.; Gotoda, H.; Dolnik, M.; Epstein, I.R. Analysis and prediction of aperiodic hydrodynamic oscillatory time series by feed-forward neural networks, fuzzy logic, and a local nonlinear predictor. Chaos 2015, 25, 013104. [CrossRef]

18. Bartolomei, B.; Heron, B.M.; Gentili, P.L. A contribution to neuromorphic engineering: Neuromodulation implemented through photochromic compounds maintained out of equilibrium by UV-visible radiation. Rend. Fis. Acc. Lincei 2020, 31, 39-52. [CrossRef]

19. Gentili, P.L. Small steps towards the development of chemical artificial intelligent systems. RSC Adv. 2013, 3, 25523-25549. [CrossRef]

20. Gentili, P.L. Boolean and fuzzy logic implemented at the molecular level. Chem. Phys. 2007, 336, 64-73. [CrossRef]

21. Gentili, P.L. Boolean and Fuzzy Logic Gates Based on the Interaction of Flindersine with Bovine Serum Albumin and Tryptophan. J. Phys. Chem. A 2008, 112, 11992-11997. [CrossRef]

22. Deaton, R.; Garzon, M. Fuzzy logic with biomolecules. Soft Comput. 2001, 5, 2-9. [CrossRef]

23. Zadegan, R.M.; Jepsen, M.D.E.; Hildebrandt, L.L.; Birkedal, V.; Kjems, J. Construction of a Fuzzy and Boolean Logic Gates Based on DNA. Small 2015, 11, 1811-1817. [CrossRef] [PubMed]

24. Gentili, P.L. The fundamental Fuzzy logic operators and some complex Boolean logic circuits implemented by the chromogenism of a spirooxazine. Phys. Chem. Chem. Phys. 2011, 13, 20335-20344. [CrossRef]

25. Pilarczyk, K.; Daly, B.; Podborska, A.; Kwolek, P.; Silverson, V.A.D.; de Silva, A.P.; Szaciłowski, K. Coordination chemistry for information acquisition and processing. Coord. Chem. Rev. 2016, 325, 135-160. [CrossRef]

26. Bhattacharjee, D.; Kim, W.; Chattopadhyay, A.; Waser, R.; Rane, V. Multi-valued and Fuzzy Logic Realization using TaOx Memristive Devices. Sci. Rep. 2018, 8, 1-10.

27. Arkin, A.; Ross, J. Computational functions in biochemical reaction networks. Biophys. J. 1994, 67, $560-578$. [CrossRef]

28. Gentili, P.L. Molecular Processors: From Qubits to Fuzzy Logic. ChemPhysChem 2011, 12, 739-745. [CrossRef]

29. Fuxreiter, M. Towards a Stochastic Paradigm: From Fuzzy Ensembles to Cellular Functions. Molecules 2018, 23, 3008. [CrossRef]

30. Liu, H.; Jeffery, C.J. Moonlighting Proteins in the Fuzzy Logic of Cellular Metabolism. Molecules 2020, $25,3440$. [CrossRef] 
31. Uversky, V.N. Supramolecular Fuzziness of Intracellular Liquid Droplets: Liquid-Liquid Phase Transitions, Membrane-Less Organelles, and Intrinsic Disorder. Molecules 2019, 24, 3265. [CrossRef]

32. Quirolo, Z.B.; Sequeira, M.A.; Martins, J.C.; Dodero, V.I. Sequence-Specific DNA Binding by Noncovalent Peptide-Azocyclodextrin Dimer Complex as a Suitable Model for Conformational Fuzziness. Molecules 2019, 24, 2508. [CrossRef] [PubMed]

33. Gentili, P.L. The fuzziness of a chromogenic spirooxazine. Dyes Pigment. 2014, 110, 235-248. [CrossRef]

34. Gambucci, M.; Gentili, P.L.; Sassi, P.; Latterini, L. A multi-spectroscopic approach to investigate the interactions between Gramicidin A and silver nanoparticles. Soft Matter 2019, 15, 6571-6580. [CrossRef] [PubMed]

35. Carvalho-Silva, V.H.; Coutinho, N.D.; Aquilanti, V. From the Kinetic Theory of Gases to the Kinetics of Rate Processes: On the Verge of the Thermodynamic and Kinetic Limits. Molecules 2020, 25, 2098. [CrossRef]

36. Machado, H.G.; Sanches-Neto, F.O.; Coutinho, N.D.; Mundim, K.C.; Palazzetti, F.; Carvalho-Silva, V.H. "Transitivity": A Code for Computing Kinetic and Related Parameters in Chemical Transformations and Transport Phenomena. Molecules 2019, 24, 3478. [CrossRef]

37. Rouvray, D.H. Fuzzy Logic in Chemistry, 1st ed.; Academic Press: San Diego, CA, USA, 1997.

38. Syropoulos, A. On vague chemistry. Found. Chem. 2020. [CrossRef]

(C) 2020 by the author. Licensee MDPI, Basel, Switzerland. This article is an open access article distributed under the terms and conditions of the Creative Commons Attribution (CC BY) license (http://creativecommons.org/licenses/by/4.0/). 